\title{
Tipps und Tricks für die Praxis
}

1. Die $4 \mathrm{~mm}$-Schanzschraube mit einer 18 Ch-Redondrainage beziehen

\section{Einfach mit einer} Universalbacke fixieren
Bei der Primärversorgung von gelenknahen Frakturen muss oftmals ein gelenküberbrückender Fixateur externe angelegt werden. Die $5 \mathrm{~mm}$ Schanzschrauben des universell einsetzbaren AO-Fixateurs sind allerdings für eine Montage sowohl auf einem Mittelhandknochen als auch auf den Metatarsalia zu groß dimensioniert. Hier wünscht man sich die Möglichkeit, auf $4 \mathrm{~mm}$ oder $3 / 4 \mathrm{~mm}$ Schanzschrauben ausweichen zu können, was aufwändige Zusatzmontagen oder teuere Spezialbacken notwendig macht. Es geht aber auch einfacher:
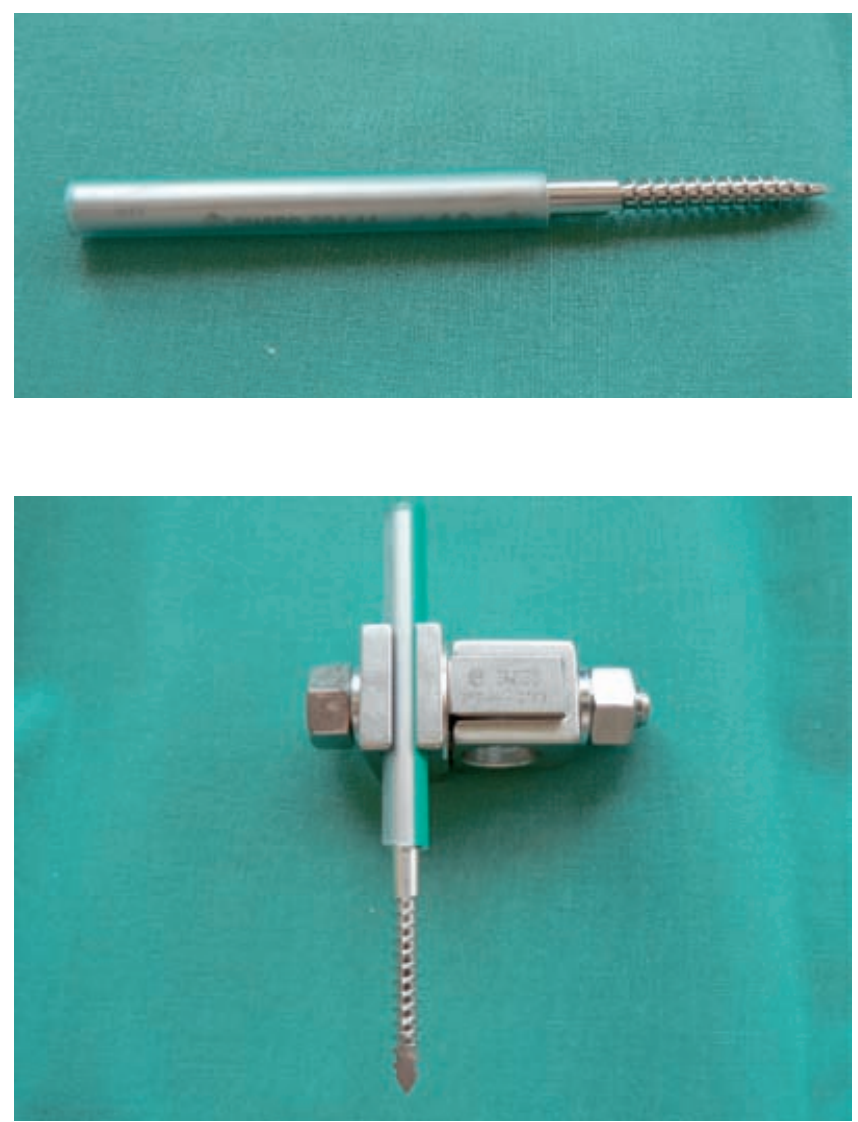

Für eine Ruhigstellung bis zur Definitivversorgung ist diese Montage ausreichend stabil, erspart die Anschaffung von teueren Zusatzbacken und spart Zeit bei der Erstversorgung.

\section{Dr. med. Jörg Schmidt}

Unfallchirurgie Berlin-Buch, Hobrechtsfelder Chaussee 100, 13125 Berlin 